\title{
A case report of primary squamous cell carcinoma of the breast
}

\author{
Xiaoli Yao ${ }^{1}$, Huihua $\mathrm{He}^{2}$, Jingping Yuan ${ }^{2}$, Feng Yao ${ }^{1}$ \\ ${ }^{1}$ Department of Breast and Thyroid Surgery, Renmin Hospital of Wuhan University, Wuhan, China; ${ }^{2}$ Department of Pathology, Renmin Hospital of \\ Wuhan University, Wuhan, China \\ Correspondence to: Feng Yao. Department of Breast and Thyroid Surgery, Renmin Hospital of Wuhan University, Wuhan 430000, China. \\ Email: yaofengrmh@163.com.
}

\begin{abstract}
Primary squamous cell carcinoma (SCC) of the breast is a metaplastic carcinoma subtype and an especially aggressive tumor with poor prognosis. Here, we present a case of locally advanced primary SCC of the breast. We reported a case of a 32-year-old woman with a palpable lump in the inner quadrant of the right breast. Core needle biopsy was performed and revealed SCC. Immunohistochemistry staining indicated that the patient had estrogen receptor (ER)-positive immunoreactivity, but was negative for both progesterone receptor and human epidermal growth factor receptor 2 (HER2). Magnetic resonance imaging (MRI) found a mass in the right breast just $4.8 \mathrm{~cm} \times 4.3 \mathrm{~cm} \times 3.4 \mathrm{~cm}$ in size. We planned neoadjuvant chemotherapy consisting of 4 cycle of nab-paclitaxel and every 3 weeks followed by 4 cycles of epirubicin and cyclophosphamide (EC) every 2 weeks. However, after 3 cycles of EC, the disease progressed, and the chemotherapy agents were switched to nab-paclitaxel and cisplatin. Still, disease progression continued, and the chemotherapy agents were changed once more to apatinib, eribulin, and camrelizumab. As this also did not work, modified radical mastectomy was performed. Postoperative pathology revealed extensive necrosis. Our case did not achieve pathologic complete response after neoadjuvant chemotherapy. We then started local radiotherapy, and then adjuvant tamoxifen treatment of $20 \mathrm{mg} /$ day followed by 6 cycles of capecitabine. No evidence of disease was detected at half-year follow-up.
\end{abstract}

Keywords: Breast cancer; neoadjuvant treatment; squamous cell carcinoma (SCC); case report

Received: 11 December 2020; Accepted: 27 April 2021; Published: 30 April 2021.

doi: $10.21037 /$ tbcr-20-67

View this article at: http://dx.doi.org/10.21037/tbcr-20-67

\section{Introduction}

Primary squamous cell carcinoma (SCC) of the breast is a metaplastic carcinoma subtype. The etiology and pathogenesis of primary SCC of breast still remains unclear. It is a particularly aggressive tumor with poor prognosis and is seen in fewer than $0.1 \%(0.04-0.075 \%)$ of all breast malignancies (1). Here, we present a case of locally advanced primary SCC of the breast. We present the following case in accordance with the CARE reporting checklist (available at http://dx.doi.org/10.21037/tbcr-20-67).

\section{Case presentation}

We report a case of a 32-year-old woman with a palpable lump in the inner quadrant of the right breast in
December 2019, which had been untreated. The mass increased rapidly without redness or swelling on the surface of the skin. In March 2020, she went to a local hospital for examination. In the hospital, color Doppler ultrasonography showed a tumor $4 \mathrm{~cm} \times 3 \mathrm{~cm}$ in size. The patient was diagnosed as metaplastic carcinoma with squamous cell component (MCSC) of the right breast by hollow needle puncture pathological examination which was delayed to April 28, 2020 due to the COVID-19 epidemic. Immunohistochemistry revealed the following: MCSC of the right breast, composed of SCC. Immunohistochemistry indicators were as follows: estrogen receptor (ER) $20 \%$, progesterone receptor (PR) negative, human epidermal growth factor receptor 2 (HER2) $0-1+$, and Ki67 50\%. On May 2020, she was transferred to our hospital (Renmin Hospital of Wuhan University) for treatment. The patient 

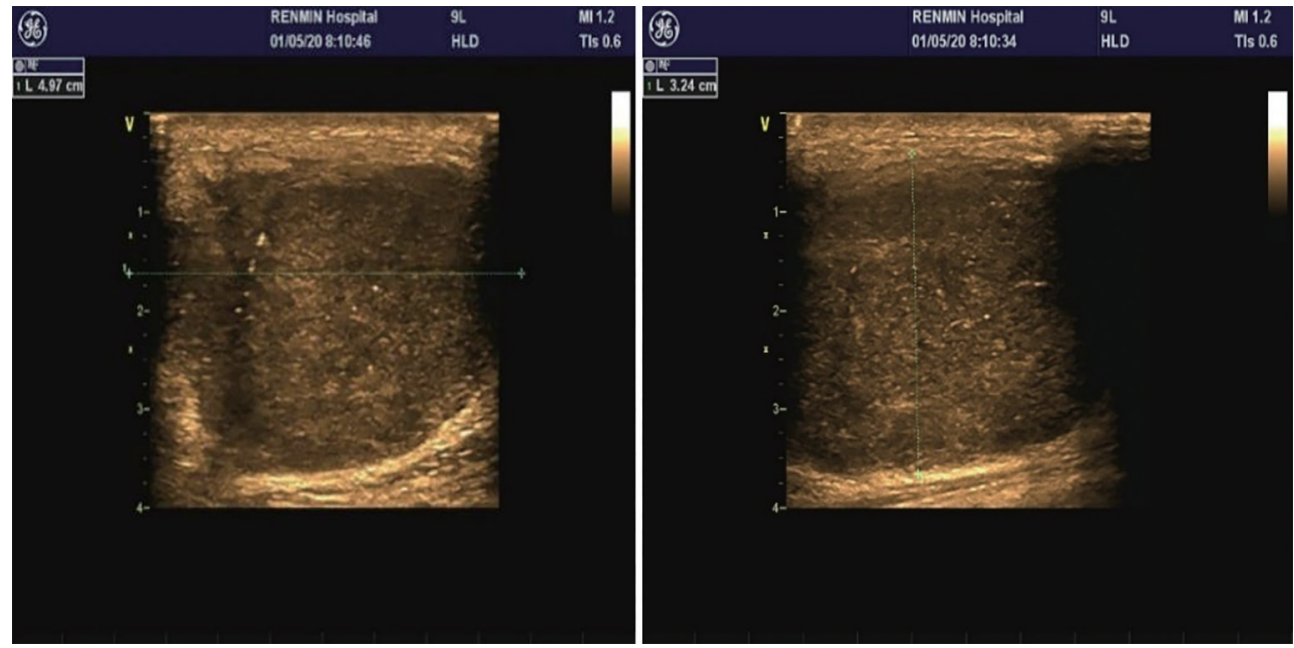

Figure 1 Color Doppler ultrasonography of the breast. Tumor size $5 \mathrm{~cm} \times 3.3 \mathrm{~cm}$.

had no history of tumor or relevant family history, and no other underlying diseases. A physical examination found a $5.0 \mathrm{~cm} \times 4.0 \mathrm{~cm}$ palpable mass in the upper right breast, which was hard, and had poor mobility and an unclear boundary. Color Doppler ultrasonography in our hospital showed a tumor $5 \mathrm{~cm} \times 3.3 \mathrm{~cm}$ in size (Figure 1) Auxiliary examinations in our hospital showed normal routine blood test results, and normal liver, kidney, and heart functions. Tumor marker CA153 was elevated to $55.6 \mathrm{U} / \mathrm{mL}$. Wholebody positron emission tomography-computed tomography (PET-CT) examination showed no distant metastasis. On May 2, 2020, a consultation on her pathological section conducted in our hospital confirmed the patient as MCSC of the breast. Immunohistochemistry revealed the following: ER20\%, PR negative, HER2 negative, Ki67 50\% (Figure 2), GATA-3 positive, GCDFP-15 negative, and myoglobin negative (Figure 3). Fine needle aspiration of the right axillary lymph node found cancer cells. The final diagnosis was the following: MCSC of the right breast, cT3N1M0 stage IIIA, luminal B, and HER2 negative. Neoadjuvant chemotherapy and intensive sequential epirubicin/cyclophosphamide (EC) regimen were administered. The ovarian function was protected by subcutaneous injection of leuprorelin during chemotherapy. According to the plan, color ultrasonography evaluation was conducted once every 2 cycles, and breast magnetic resonance imaging (MRI) evaluation was conducted once every 4 cycles (Figure 4). According to the Response Evaluation Criteria in Solid Tumors (RECIST), the disease progressed. The baseline tumor diameter was $4.8 \mathrm{~cm}$ before chemotherapy. After 3 cycles of neoadjuvant chemotherapy (May 1, 2020; May 15, 2020; May 29, 2020) using an intensive epirubicin dose $\left(160 \mathrm{mg}, 100 \mathrm{mg} / \mathrm{m}^{2}\right)$ and cyclophosphamide $\left(960 \mathrm{mg}, 600 \mathrm{mg} / \mathrm{m}^{2}\right)$, the tumor diameter was $6.5 \mathrm{~cm}$ (Figure 4). A pathological examination using core needle biopsy was performed. The results were as follows: ER20\%, PR negative, HER2 negative, Ki67 50\% (Figure 5), and disease progress. As there was no change in the pathological indicators, the chemotherapy regimen was changed. On June 14, the nab-paclitaxel (400 mg, $\left.260 \mathrm{mg} / \mathrm{m}^{2}\right)+$ cisplatin $\left(120 \mathrm{mg}, 75 \mathrm{mg} / \mathrm{m}^{2}\right)$ regimen was started for 1 cycle of treatment. From July 1, apatinib (250 mg, qd, po), eribulin ( $\left.2 \mathrm{mg}, 1.2 \mathrm{mg} / \mathrm{m}^{2}, \mathrm{~d} 1,8\right)$ and camrelizumab $(200 \mathrm{mg})$ were used. The tumor diameter was $7.5 \mathrm{~cm}$, indicating further disease progression (Figure 6). On August 2, 2020, a modified radical mastectomy of the right breast was performed (Figure 7). Postoperative pathological examination revealed the following: high grade MCSC of the right breast, with vessel carcinoma embolus positive, a tumor size of $6.5 \mathrm{~cm} \times 6 \mathrm{~cm}$, ER5\%, PR negative, HER2 negative, Ki67 70\% (Figure 8), and 1/24 metastasis of the right axillary lymph node. Neoadjuvant therapy response by pathological examination was determined to be MillerPayne (MP) class 2 and residual cancer burden (RCB) level III. American Joint Committee on Cancer (AJCC) ypTN stage was ypT3N1a. The SP142 test indicated the patient was programmed death-ligand 1 (PD-L1) positive. Postoperative gross examination revealed a massive necrotic hematoma in the tumor capsule (Figure 9), which was consistent with the breast MRI evaluation (Figure 4). The 


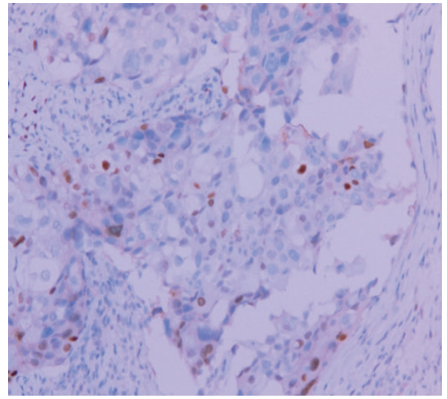

ER20\%

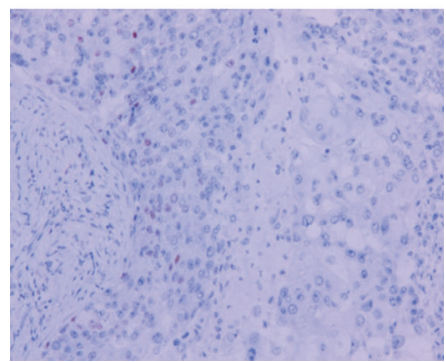

ER5\%

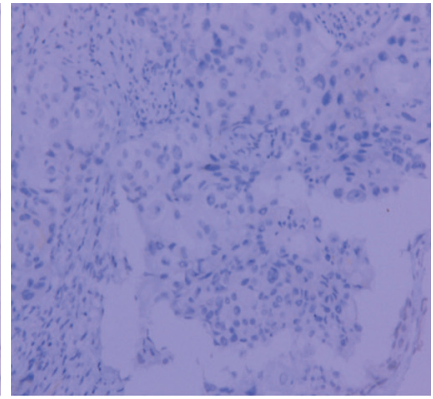

PR negative

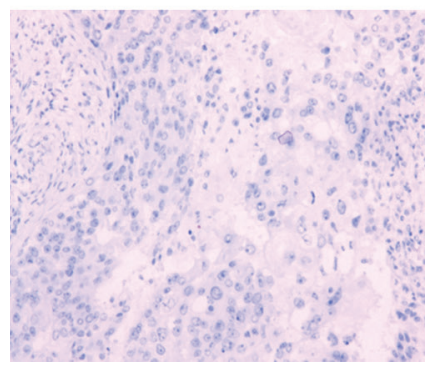

PR negative

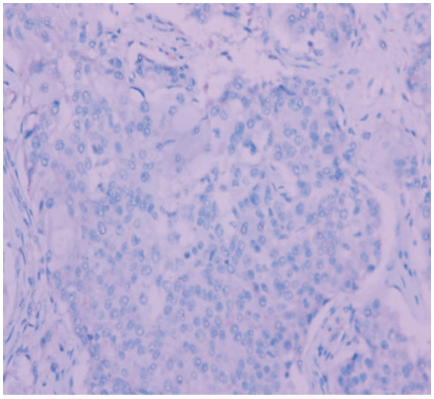

HER2 negative

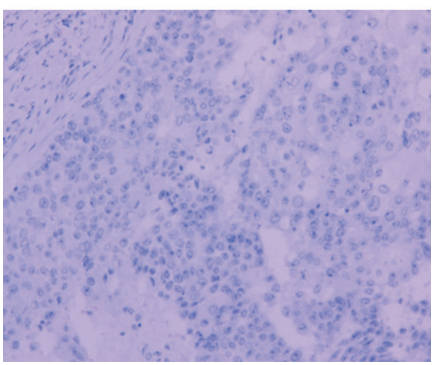

HER2 negative

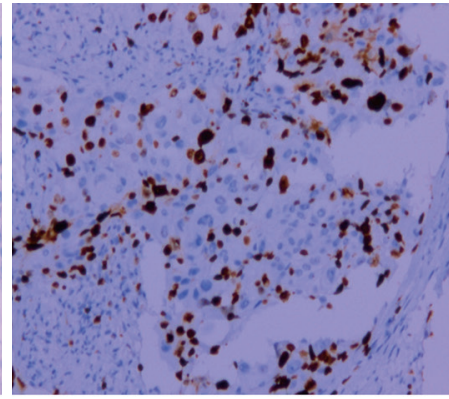

Ki67 50\%

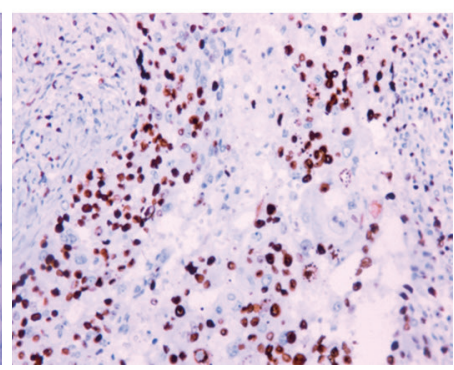

Ki67 70\%

Figure 2 Above: before chemotherapy, ER, PR, HER2, Ki67 status, HE $\times 100$. Below: after five cycles of chemotherapy ER, PR, HER2, Ki67 status, HE $\times 100$. ER, estrogen receptor; PR, progesterone receptor; HER2, human epidermal growth factor receptor 2; HE, hematoxylin-eosin staining.

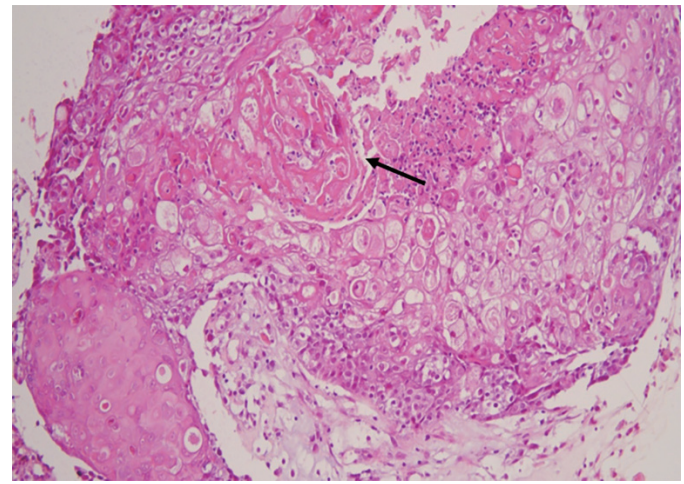

Figure 3 Baseline pathological results for consultation before chemotherapy. The infiltrating carcinoma was characterized by nests of infiltrating stroma, and the cancer cells had characteristics of squamous-cell carcinoma, with abundant cytoplasm, visible intercellular bridges, keratinization, and inflammatory cell infiltrates observed in the stroma. HE $\times 200$ (with arrow indicating keratinization).

MRI T2 signal diagram and diffusion-weighted imaging (DWI) signal diagram showed that the area with high signals was gradually shrinking; meanwhile, the breast MRI indicated that the tumor component was also shrinking, the necrotic bleeding range was increasing, and a large hematoma had formed. In combination with the above treatment and postoperative pathological examination, it was clear that the chemotherapy had limited efficacy on MCSC of the breast and was creating difficulties in postoperative treatment. Therefore, a polygenic test for guiding the follow-up treatment was recommended. Foundation-1 polygenic test results showed microsatellite (MS)-stable and no tumor mutation burden (TMB) related to immunotherapy, which was consistent with the negative PD-L1 finding from by postoperative pathological immunohistochemistry. PIK3CA, PTEN, and FGFR1 mutations related to drug resistance were also found, while BRCA1 and BRCA2 were not mutated (Figure 10). The genetic test results showed drug resistance, which was consistent with the results of the previous treatment period. All procedures performed in studies involving human participants were in accordance with the ethical standards of the institutional and/or national research committee(s) and with the Helsinki Declaration (as revised in 2013). The patient has given the consent for the case report to be published. 


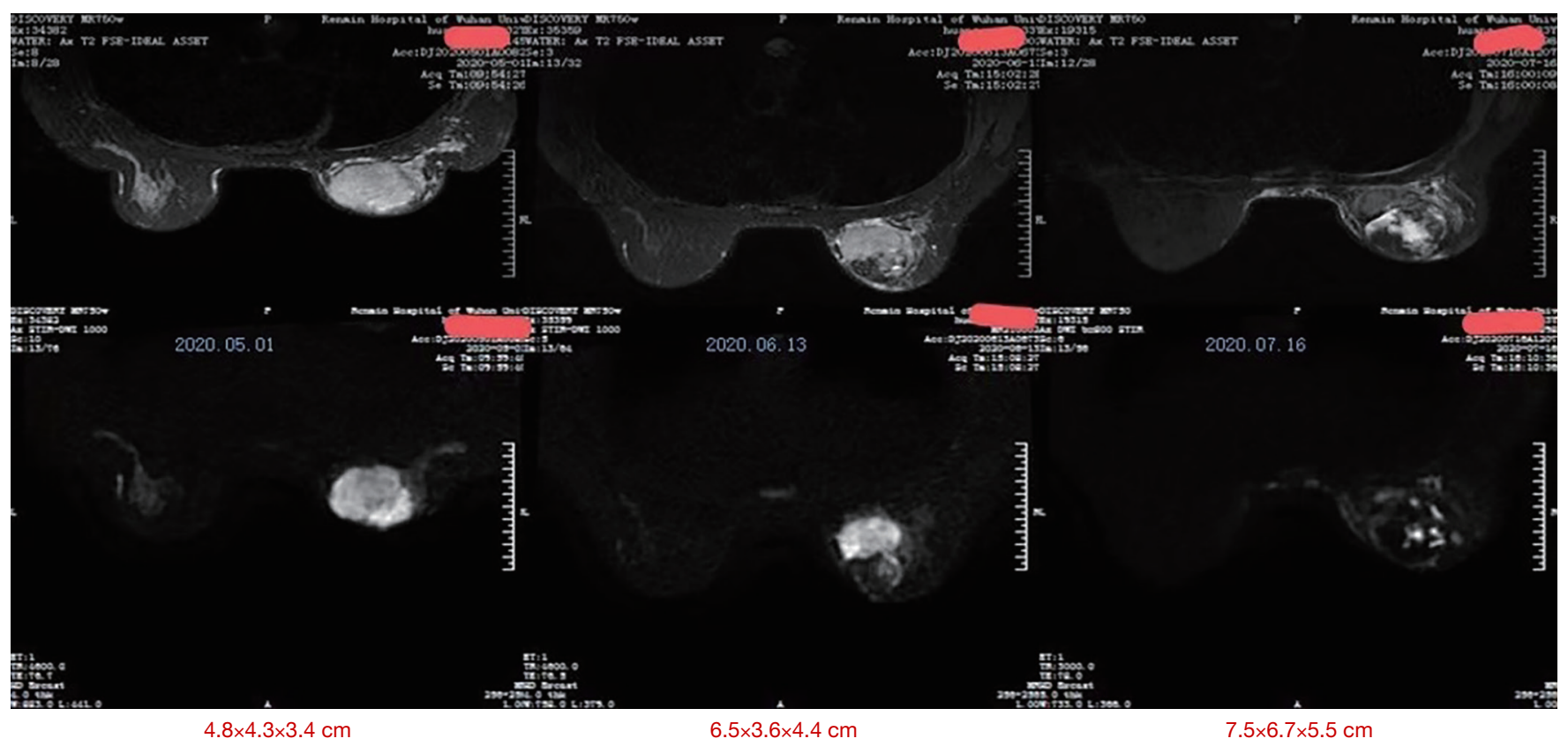

Figure 4 Breast MRI The maximum size of the tumor was assessed on MRI before chemotherapy, 3 cycles after chemotherapy and 5 cycles after chemotherapy, Above: T2 signal. Below: DWI. Left: baseline tumor diameter $4.8 \mathrm{~cm}$ before chemotherapy; middle: $6.5 \mathrm{~cm}$ after 3 -cycle EC chemotherapy, and $7.5 \mathrm{~cm}$ after 5-cycle EC chemotherapy. MRI, magnetic resonance imaging; DWI, diffusion-weighted imaging.
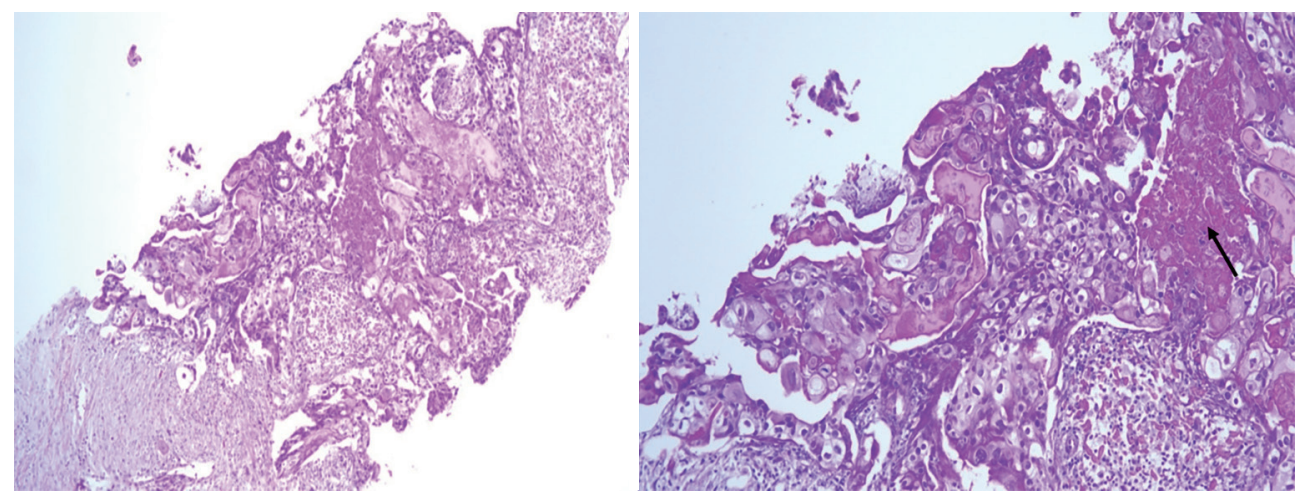

Figure 5 Pathological assessment. Biopsy after 3 cycles of EC chemotherapy. Left: microscopic necrosis in the nests, HE $\times 100$. Right: microscopically, the cancer cells varied in size, with some nuclei shrunken, accompanied by keratinization and necrosis, HE $\times 200$ (with arrow indicating necrosis). EC, epirubicin and cyclophosphamide.

\section{Discussion}

The patient was diagnosed with MCSC, which is a type of bio-SCC, known as metaplastic breast carcinoma (MPBC). The incidence rate of MPBC is very low, accounting for just $0.2-5 \%$ of breast carcinoma (2) cases, and thus the incidence rate of MCSC is even lower. MPBC consists of ductal epithelial cells, squamous cells and/or chondroid cells, and spindle cells, with SCC being the most common histologic subtype (3). MPBC usually occurs among women above 50 years old, and presents as a rapidly growing breast mass (4) as compared to invasive ductal carcinoma (IDC). Locally advanced metaplasia may be found in about $90 \%$ of the patients, $50 \%$ of whom will have secondary distant metastasis. The risk of metastasis is twice that of triplenegative breast cancer (TNBC) $(5,6)$. About $10 \%$ of MPBC 


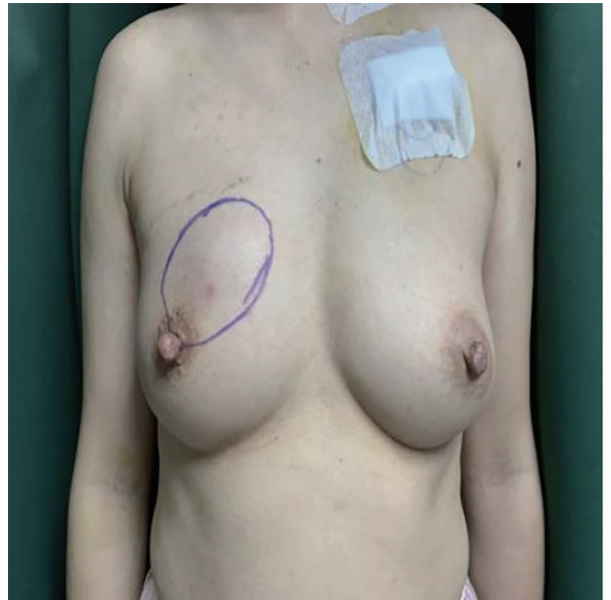

Baseline before chemotherapy

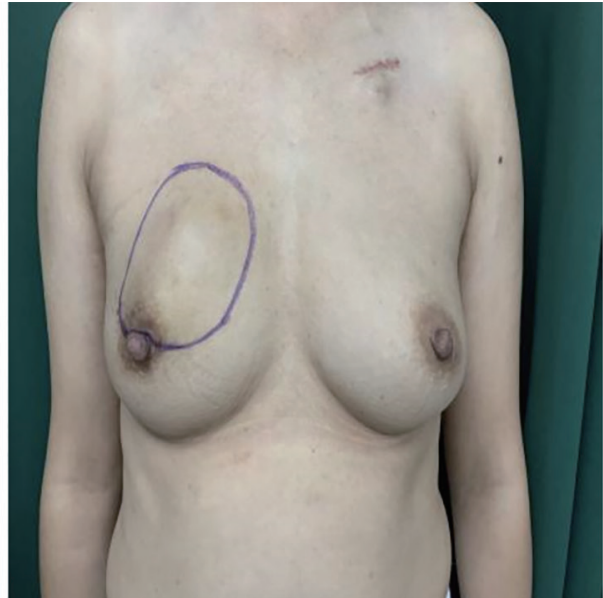

After 3EC regimen

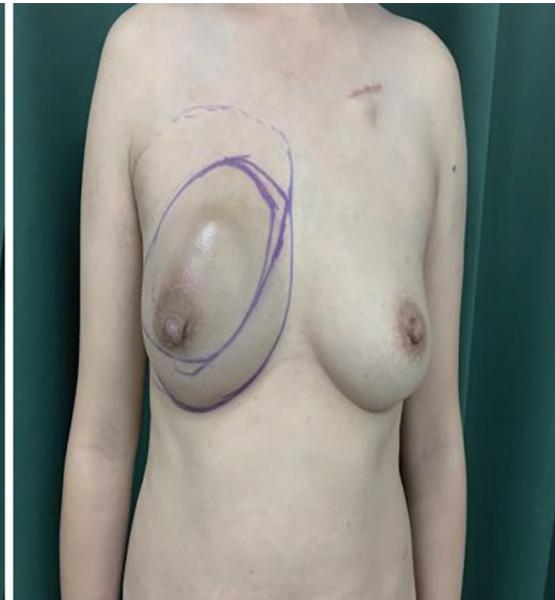

After the 4th cycle of nab-paclitaxel + cisplatin and the 5th cycle of apatinib, eribulin and camrelizumab

Figure 6 Before and after treatment.

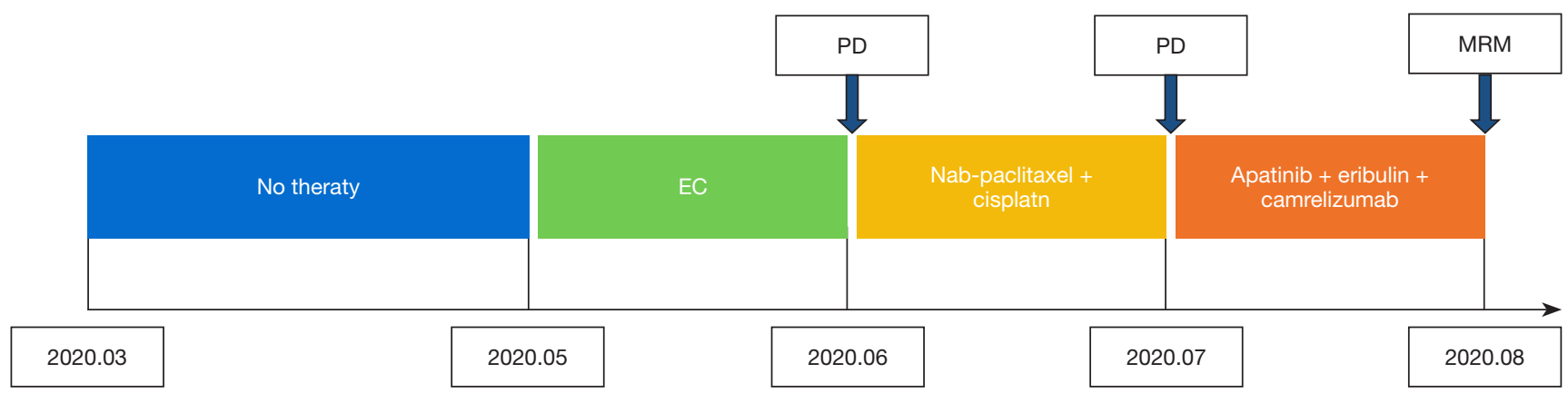

Figure 7 Timeline of the patient's treatments. EC, epirubicin and cyclophosphamide; PD, progression disease; MRM, modified radical mastectomy.

patients have distant metastasis at initial diagnosis, but the probability of axillary lymph node metastasis is low compared with that of other types of breast cancer, and about $15-20 \%$ of cases show axillary lymph node metastasis $(7,8) . \mathrm{MPBC}$ has a high incidence rate of lung metastasis as compared to TNBC ( $42 \%$ vs. $18 \%$ ) (9). MPBC tends to have a worse outcome than TNBC, with an average overall survival (OS) less than 1 year if metastasis occurs. The OS was as low as 3.4 months in some studies (10-12), while the 5 -year OS was found to be $89 \%$ for IDC, $73 \%$ for TNBC, and $54-69 \%$ for MPBC $(6,13,14)$. For MPBC, a tumor size greater than $5 \mathrm{~cm}$, lymph node metastasis, and high $\mathrm{Ki}-67$ are high risk factors, which indicate poor 5-year OS and progression-free survival (PFS) (6).
The study of Tray et al. included the largest MPBC dataset by far (15). They confirmed that most MPBCs have a low TMB, are MS-stable, are enriched with TP53 and PIK3CA mutations, and have a $65 \%$ TP53 mutation rate and a $35 \%$ PIK3CA mutation rate. In a single-center study, patients with PIK3CA-mutated tumors had a poorer prognosis than those with PIK3CA wild-type tumors (16). However, when treated with liposome doxorubicin, bevacizumab, and mTOR inhibitors (everolimus), patients with PIK3CA mutation had a significantly higher objective response rate compared with those without the mutation (17). In MPBC, the Tp53 mutation indicates a better clinical prognosis than that of the Tp53 wild type (18). It is speculated that the Tp53 mutation can predict the sensitivity 

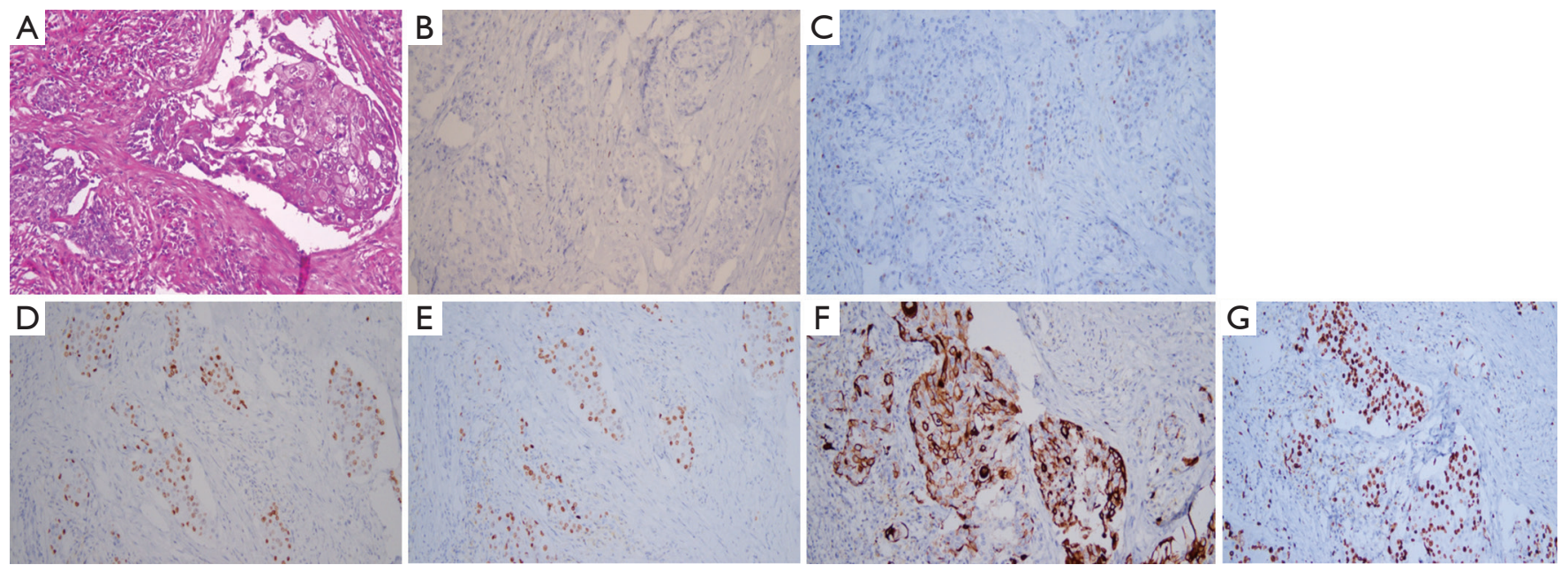

Figure 8 Pathology after radical mastectomy. (A) The nests of carcinoma showed squamous cell differentiation, with keratinization, HE $\times 200$; (B) AR and PR negative; (C) moderate ER, with a positive rate of approximately 5\%; (D) P40 positive, IHC $\times 200$; (E) P63 positive, $\mathrm{IHC} \times 200$; (F) CK5/6 positive $\mathrm{IHC} \times 200 ;(\mathrm{G}) \mathrm{Ki67}$ positive rate: about $70 \%, \mathrm{IHC} \times 200$.

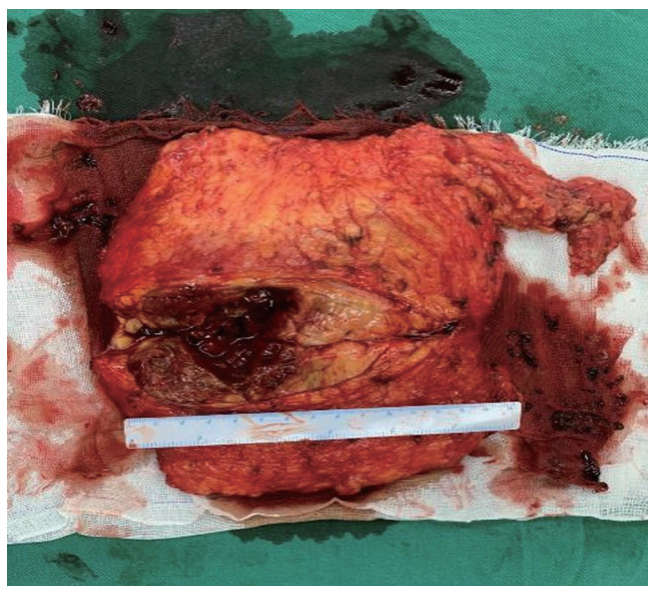

Figure 9 Postoperative gross examination: a mass of necrotic blood clots can be seen in the center of the tumor.

to antiangiogenic drug therapy (19) although these findings need to be verified by a further large-sample studies. In addition, most MPBC patients have low TMB and MSstable indicators. The above studies are consistent with the genetic test results of this patient.

MPBC has a poor response to neoadjuvant chemotherapy, and the pathologic complete response rate is only $11 \%$, which is lower than that of TNBC. Patients with MPBC should be included in relevant clinical trials for new neoadjuvant regimens. In the absence of clinical trials, if MPBC lesions can be removed, an operation may be

Biomarker Findings
Microsatellite status-MS-Stable
Tumor Mutational Burden - 0 Muts/Mb
Genomic Findings
For a complete list of the genes assayed, please refer to the Appendix.
PIK3CA H1047R
PTEN T319fs*1
FGFR1 amplification
MYC amplification
KEL E239*
NSD3 (WHSC1L1) amplification
RAD21 amplification
TP53 R209fs 6
ZNF703 amplification
3 Disease relevant genes with no reportable alterations: BRCA1,
BRCA2, ERBB2

Figure 10 F1CDX test: the patient had zero TMB and are microsatellite stable and was enriched with PIK3CA and PTEN and FGFR1 mutations. *, premature translation termination codons. TMB, tumor mutation burden.

performed directly (20). The results of the largest scale MPBC study thus far, conducted in the United States, indicated that adjuvant radiotherapy should be given to patients with pT3-4 or lymph node positive after lumpectomy (21).

Based on the above analysis, as with IDC, surgery, 
Table 1 Selected trials for consideration of MPBC

\begin{tabular}{|c|c|c|c|}
\hline Trial (Clinicaltrials.gov NCT) & Treatment setting & Therapeutic agents & MPBC or TNBC \\
\hline DART Trial (NCT02834013) & Metastatic & Nivolumab and Ipilimumab & MPBC \\
\hline $\begin{array}{l}\text { Morpheus-TNBC } \\
\text { (NCT03424005) }\end{array}$ & Metastatic & $\begin{array}{l}\text { Multiple immunotherapy- } \\
\text { based treatment } \\
\text { combinations }\end{array}$ & TNBC \\
\hline
\end{tabular}

Little data is available regarding the efficacy of neoadjuvant regimens in MPBC. MPBC, metaplastic breast cancer; NAC, neoadjuvant chemotherapy; PD-1, programmed cell death protein 1; PD-L1, programmed death ligand 1; TNBC, triple negative breast cancer.

chemotherapy and radiotherapy are still the main means of MPBC treatment, but the survival rate is relatively low, indicating that there are still no effective treatment methods. At present, several MPBC-related clinical trials are ongoing (Table 1). For MPBC patients, the effect of neoadjuvant therapy is poor; their conditions progress rapidly, and are usually accompanied by multiple genetic changes of poor prognosis. For these patients, surgery should be performed as soon as possible if their conditions still progress during neoadjuvant chemotherapy. Further clinical studies need to be conducted to improve treatment efficacy.

\section{Conclusions}

Primary SCC of the breast is a very rare disease with no standard treatment approach. If disease progression continues under neoadjuvant chemotherapy, timely surgery should be strongly considered.

\section{Acknowledgments}

Funding: None.

\section{Footnote}

Reporting Checklist: The authors have completed the CARE reporting checklist. Available at http://dx.doi.org/10.21037/ tbcr-20-67
Conflicts of Interest: All authors have completed the ICMJE uniform disclosure form (available at http://dx.doi. org/10.21037/tbcr-20-67). The authors have no conflicts of interest to declare.

Ethical Statement: The authors are accountable for all aspects of the work in ensuring that questions related to the accuracy or integrity of any part of the work are appropriately investigated and resolved. All procedures performed in studies involving human participants were in accordance with the ethical standards of the institutional and/or national research committee(s) and with the Helsinki Declaration (as revised in 2013). The patient has given the consent for the case report to be published.

Open Access Statement: This is an Open Access article distributed in accordance with the Creative Commons Attribution-NonCommercial-NoDerivs 4.0 International License (CC BY-NC-ND 4.0), which permits the noncommercial replication and distribution of the article with the strict proviso that no changes or edits are made and the original work is properly cited (including links to both the formal publication through the relevant DOI and the license). See: https://creativecommons.org/licenses/by-nc-nd/4.0/.

\section{References}

1. Bhosale SJ, Kshirsagar AY, Deshmukh SJ, et al. Squamous cell carcinoma of the breast. Am J Case Rep 
2013;14:188-90.

2. Lakhani SR, Schnitt SJ, Tan PH, et al. Metaplastic carcinoma. WHO classification of tumours of the breast. Fourth ed. International Agency for Research on Cancer (IARC) 2012:48-52.

3. Weigelt B, Eberle C, Cowell CF, et al. Metaplastic breast carcinoma: more than a special type. Nat Rev Cancer 2014;14:147-8.

4. Bian T, Lin Q, Wu Z, et al. Metaplastic carcinoma of the breast: Imaging and pathological features. Oncol Lett 2016;12:3975-80.

5. El Zein D, Hughes M, Kumar S, et al. Metaplastic carcinoma of the breast is more aggressive than triplenegative breast cancer: a study from a single institution and review of literature. Clin Breast Cancer 2017;17:382-91.

6. Abouharb S, Moulder S. Metaplastic breast cancer: clinical overview and molecular aberrations for potential targeted therapy. Curr Oncol Rep 2015;17:431.

7. Langlands F, Cornford E, Rakha E, et al. Imaging overview of metaplastic carcinomas of the breast: a large study of 71 cases. Br J Radiol. 2016;89:20140644.

8. Pezzi CM, Patel-Parekh L, Cole K, et al. Characteristics and treatment of metaplastic breast cancer: analysis of 892 cases from the National Cancer Data Base. Ann Surg Oncol 2007;14:166-73.

9. He X, Ji J, Dong R, et al. Prognosis in different subtypes of metaplastic breast cancer: a population-based analysis. Breast Cancer Res Treat 2019;173:329-41.

10. Jung SY, Kim HY, Nam BH, et al. Worse prognosis of metaplastic breast cancer patients than other patients with triple-negative breast cancer. Breast Cancer Res Treat 2010;120:627-37.

11. Rayson D, Adjei AA, Suman VJ, et al. Metaplastic breast cancer: prognosis and response to systemic therapy. Ann Oncol 1999;10:413-9.

12. Takala S, Heikkilä P, Nevanlinna H, et al. Metaplastic carcinoma of the breast: Prognosis and response to

doi: $10.21037 /$ tbcr-20-67

Cite this article as: Yao X, He H, Yuan J, Yao F. A case report of primary squamous cell carcinoma of the breast. Transl Breast Cancer Res 2021;2:16. systemic treatment in metastatic disease. Breast J 2019;25:418-24.

13. Cimino-Mathews A, Verma S, Figueroa-Magalhaes MC, et al. A clinicopathologic analysis of 45 patients with metaplastic breast carcinoma. Am J Clin Pathol 2016;145:365-72.

14. Leyrer CM, Berriochoa CA, Agrawal S, et al. Predictive factors on outcomes in metaplastic breast cancer. Breast Cancer Res Treat 2017;165:499-504.

15. Tray N, Taff J, Singh B, et al. Metaplastic breast cancers: Genomic profiling, mutational burden and tumorinfiltrating lymphocytes. Breast 2019;44:29-32.

16. Afkhami M, Amanam IU, Aoun PA, et al. Genomic profiling of metaplastic breast cancer: a single center experience. J Clin Oncol 2017;35:e12041.

17. Basho RK, Gilcrease M, Murthy RK, et al. Targeting the PI3K/AKT/mTOR Pathway for the Treatment of Mesenchymal Triple-Negative Breast Cancer: Evidence From a Phase 1 Trial of mTOR Inhibition in Combination With Liposomal Doxorubicin and Bevacizumab. JAMA Oncol 2017;3:509-15.

18. Vallecillo LB, Chang JT, Chen K, et al. Whole exome sequencing of metaplastic breast cancer (MpBC): effect of mutation status on survival. J Clin Oncol 2017;35:abstr 1090.

19. Wheler JJ, Janku F, Naing A, et al. TP53 Alterations Correlate with Response to VEGF/VEGFR Inhibitors: Implications for Targeted Therapeutics. Mol Cancer Ther 2016;15:2475-85.

20. Al-Hilli Z, Choong G, Keeney MG, et al. Metaplastic breast cancer has a poor response to neoadjuvant systemic therapy. Breast Cancer Res Treat 2019;176:709-16.

21. Haque W, Verma V, Naik N, et al. Metaplastic Breast Cancer: Practice Patterns, Outcomes, and the Role of Radiotherapy. Ann Surg Oncol 2018;25:928-36.

(English Language Editor: J. Gray) 